Check for updates

Cite this: RSC Adv., 2018, 8, 14806

Received 27th February 2018

Accepted 5th April 2018

DOI: $10.1039 / \mathrm{c} 8 \mathrm{ra01720d}$

rsc.li/rsc-advances

\title{
Preparation of metallic monolithic Pt/FeCrAl fiber catalyst by suspension spraying for VOCs combustion
}

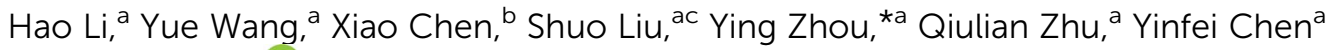 \\ and Hanfeng Lu (D)*a
}

\begin{abstract}
We report a facile and general strategy for the preparation of metallic monolithic catalysts. Our strategy involved subjecting the surfaces of FeCrAl fibers to thermal treatment and the spraying of $\mathrm{Pt}$ nanoparticles suspension liquid. The catalyst exhibited high catalytic activity and good stability in the combustion of volatile organic compounds to $\mathrm{CO}_{2}$ and $\mathrm{H}_{2} \mathrm{O}$ at mild temperature. The exceptional activity of the catalyst can be attributed to the well-adhered alumina coating that formed on the surfaces of the FeCrAl fibers after thermal treatment and the highly dispersed Pt nanoparticles on the surface of the alumina coating.
\end{abstract}

\section{Introduction}

As one of the major components of air pollution, volatile organic compounds (VOCs) are both precursors of ozone and photochemical smog and substances that are toxic to human health. ${ }^{1-4}$ One of the most effective and economically feasible VOC removal technologies is catalytic combustion because catalytic oxidation leads to degradation of VOCs to $\mathrm{CO}_{2}$ and $\mathrm{H}_{2} \mathrm{O}$ and it is suitable for operation with dilute VOC effluent streams $\left(<1 \%\right.$ VOCs).$^{5-8}$ Monolithic catalysts are widely used in catalytic combustion due to their good attrition resistance and very low pressure drop even under high flow rate. Monoliths are commonly composed of ceramics or metallic materials., ${ }^{\mathbf{9} 10}$ Metallic materials exhibit higher thermal conductivity and mechanical resistance, better electrical conductivity, and lower manufacturing costs than ceramic materials. ${ }^{11,12}$ Given these advantages, the application of metallic substrates as catalyst supports is becoming increasingly common..$^{13-15}$ Monolithic catalysts are prepared through electrophoretic deposition, ${ }^{16}$ anodisation, ${ }^{17}$ or steam-only oxidation..$^{18}$ Lu et al. reported a facile, versatile, and cost-effective one-step route for the fabrication of a composite system of hierarchically structured AlOOH 2D-nanosheets on a paper-like 3D network based on Alfibers. Their method is aided by the steam-only oxidation of Al. The Al-fiber@ns-AlOOH@Pd catalyst presents high intrinsic activity for the oxidative coupling of CO to DMO. ${ }^{19}$

\footnotetext{
Innovation Team of Air Pollution Control, Institute of Catalytic Reaction Engineering, College of Chemical Engineering, Zhejiang University of Technology, Hangzhou 310014, China. E-mail: wjfx@zjut.edu.cn; luhf@zjut.edu.cn; Tel: +8657188320767 ${ }^{b}$ College of Environment, Zhejiang University of Technology, China

${ }^{c}$ Hangzhou Runxing Technology Co., Ltd, Hangzhou, China
}

However, several important issues in the fabrication of metallic monolithic catalysts for VOC combustion remain unresolved. These issues include (1) the process complexity and poor adhesion of conventional wash-coating methods ${ }^{20-23}$ and (2) the limitation of active component loading due to the shape of the carrier. The preparation flow of the metallic monolithic catalyst is cumbersome: the active species is loaded through impregnation or through a slurry, which is prepared from a powder catalyst and directly coated on the surface of a metallic substrate; then, the monolithic catalyst is obtained through activation treatment. Existing methods for the fabrication of metallic monolithic catalysts require complex and enormous effort to load the active species on the catalyst supports. Nevertheless, active noble metal nanoparticles (NPs) prepared in liquid form can be randomly loaded through a simple spraying method. Moreover, the deactivated catalyst will not require replacement because it can be reactivated through respraying. This method is very economic and convenient, and it can save raw material costs.

Herein, we synthesized Pt NPs dispersion suspension via solvent-thermal method. ${ }^{24-26} \mathrm{~A}$ well-adhered alumina coating formed on the surface of FeCrAl fibers after thermal treatment at $950{ }^{\circ} \mathrm{C}$ in $\mathrm{O}_{2}$ atmosphere and active NPs were loaded on FeCrAl fibers through simple spraying. Pt NPs were highly dispersed on the surface of the metallic substrate with a monomolecular membrane structure and were firmly bonded on the metallic substrate after calcination (Fig. 1). We evaluated the catalytic performance of the as-synthesized catalyst in the catalytic combustion of toluene, which was used as a model VOC. Our catalyst can exhibit activity toward other VOCs and may enable the significant advancement of VOC removal technologies..$^{27,28}$ 


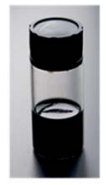

Pt NPs dispersion liquid

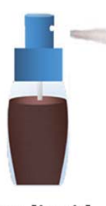

Fig. 1 The scheme for

\section{Experimental section}

\subsection{Catalyst preparation}

Dinitrodiammineplatinum ammoniacal (DPA, $34.6 \mathrm{mg}$ ) was mixed with $3 \mathrm{~mL}$ oleyl amine (OA) and $2 \mathrm{~mL}$ oleic acid (OC) in a three-necked flask equipped with a condenser and a stir bar, followed by heating and holding at $200{ }^{\circ} \mathrm{C}$ for $3 \mathrm{~h}$ under flowing $\mathrm{N}_{2}$ atmosphere. The particles thus formed were purified by precipitation in ethanol, centrifuged (6000 rpm, $5 \mathrm{~min}$ ), washed with ethanol, and re-dispersed in $10 \mathrm{~mL} n$-hexane.

The FeCrAl fiber ( $\sim 1.3 \mathrm{~mm}$ in thickness) consisting of $7 \% \mathrm{Al}$ and $85 \mathrm{vol} \%$ voids was utilized as the substrate, which was taken from Kunshan Fangdou Net-structured Material Co. Ltd. (China). The FeCral fiber was machined to 6 circular chips $(15 \mathrm{~mm}$ in diameter, about $2.0 \mathrm{~g}$ ). Then, FeCrAl fiber was immersed in acetone, $10 \mathrm{wt} \% \mathrm{NaOH}$, and $10 \mathrm{wt} \% \mathrm{HNO}_{3}$ with ultrasonic treatment for $30 \mathrm{~min}$, in sequence. Subsequently, FeCrAl fiber was calcined in $\mathrm{O}_{2}$ atmosphere at $950{ }^{\circ} \mathrm{C}$ for $3 \mathrm{~h}$. A ready-made $\mathrm{Pt}$ nanoparticles dispersion liquid was supported on FeCrAl fiber by spraying; then, the monolithic catalyst was dried at $110{ }^{\circ} \mathrm{C}$ for $2 \mathrm{~h}$ and calcined at $500{ }^{\circ} \mathrm{C}$ for $5 \mathrm{~h}$. The loading of Pt was $0.1 \mathrm{wt} \%$ (it refers to theoretical value), the monolithic catalyst is denoted as $0.1 \mathrm{Pt} / \mathrm{FeCrAl}$ fiber.
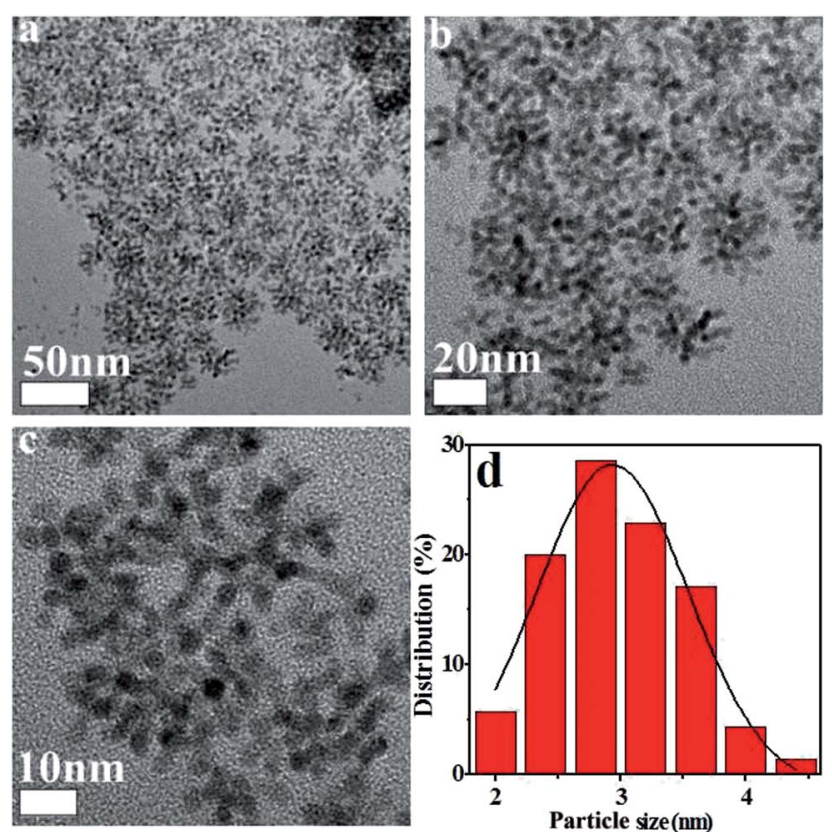

Fig. 2 TEM images of Pt NPs $(a-c)$ and corresponding size histograms (d).

\subsection{Catalyst characterization}

Transmission electron microscopy (TEM) images were taken on a Tecnai G2 F30 S-Twin (Philips-FEI, Netherlands) transmission electron microscope at acceleration voltage of $200 \mathrm{kV}$. The samples were dispersed in ethanol assisted by an ultrasonic technique. Scanning electron microscopy (SEM) and energydispersive X-ray spectroscopy (EDS) analysis were performed on a Hitachi-SU8010 SEM with acceleration voltage of $5 \mathrm{kV}$ for imaging and $15 \mathrm{kV}$ for EDS collection. The X-ray diffraction (XRD) patterns were recorded on an X'pert PRO diffractometer (PAN-alytical, Netherlands) using $\mathrm{Cu} \mathrm{K}_{\alpha}$ radiation at a generator voltage of $40 \mathrm{kV}$ and tube current of $40 \mathrm{~mA}$. The samples were scanned in the $2 \theta$ range of $10-80^{\circ}$ with scanning speed of $0.02^{\circ}$ $\mathrm{s}^{-1}$. Diffraction peaks were compared with the standard Joint Committee on Powder Diffraction Standards (JCPDS) database reported by the International Centre for Diffraction Data (ICDD). The adhesion of samples was evaluated using ultrasound tests by immersing the samples in water and applying ultrasound for $1 \mathrm{~h}$. After the samples were dried at $110^{\circ} \mathrm{C}$ for $2 \mathrm{~h}$ and calcined at $500{ }^{\circ} \mathrm{C}$ for $2 \mathrm{~h}$, the weight loss was measured.

\subsection{Catalytic activity measurement}

The activities of catalysts were tested for VOC catalytic combustion in a fixed-bed stainless steel tubular reactor (internal diameter $16 \mathrm{~mm}$ and length $350 \mathrm{~mm}$ ). In each test run, circular chips of the metallic monolithic catalyst were packed layer-by-layer into the stainless steel tubular reactor, while a Ktype thermocouple was placed in the middle of the reactor. For this experiment, we used $2.0 \mathrm{~g}$ of catalyst with a total flow rate of the feed stream at $347 \mathrm{~mL} \mathrm{~min}^{-1}$, providing a space velocity of $10000 \mathrm{~mL} \mathrm{~h}^{-1} \mathrm{~g}^{-1}$. The feed stream containing $2500 \mathrm{ppm}$ VOCs was generated by bubbling air through a saturator containing pure VOCs chilled in an ice-water isothermal bath, and then diluted with another air stream by the mass flow controller. The concentration of VOCs at the outlet of the reactor was monitored with a gas chromatograph (Kexiao, GC1620) equipped with a flame ionization detector (FID). The concentration of the oxidative product $\left(\mathrm{CO}_{2}\right)$ was monitored with a mass spectrograph (MKS Cirrus 2). The removal of VOCs was calculated on the basis of the VOCs consumption. The removal efficiency of VOCs was calculated using the following equation: (a)

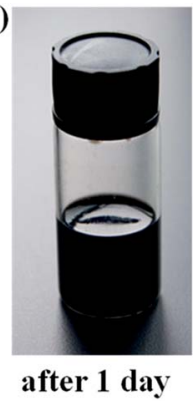

(b)

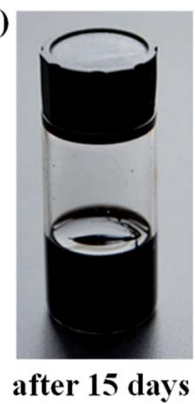

(c)

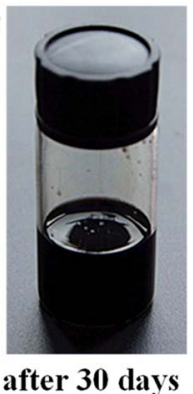

Fig. 3 Photographs of the as-prepared Pt NPs dispersion liquid after 1 day (a), 15 days (b), and 30 days (c). 


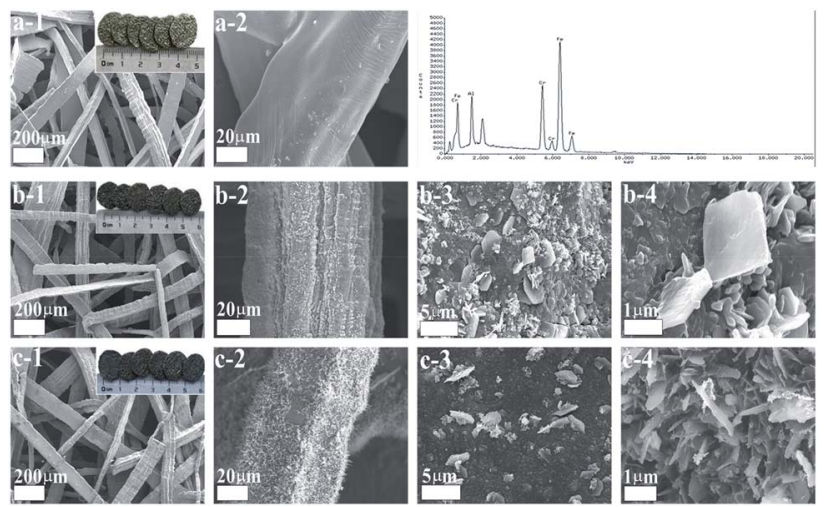

Fig. 4 SEM images (EDS results) of FeCrAl fiber (a), calcined FeCrAl fiber (b), 0.1Pt/FeCrAl fiber (c).

$$
\begin{aligned}
& \text { VOCs conversion }(\%)=[\mathrm{VOCs}]_{\text {in }}-[\mathrm{VOCs}]_{\text {out }} / \\
& {[\mathrm{VOCs}]_{\text {in }} \times 100 \% . }
\end{aligned}
$$

\section{Results and discussion}

\subsection{TEM characterization}

Fig. 2 shows TEM images of the Pt NPs, which appear spherical in shape with low aggregation and narrow size distribution. ${ }^{29,30}$ The average sizes of Pt NPs were in the range of 2-4 nm. The monodispersed structure of Pt NPs promoted their dispersal in liquid. Simple spraying was used to randomly load the active species in the VOCs purification system. In addition, the Pt NPs dispersion liquid was extremely stable. It could be stored for 1030 days without delamination and sol destruction. The storage behavior of the Pt NPs dispersion liquid indicated that it could be continuously used for long periods without changing (Fig. 3). Furthermore, this method is generally applicable and could be easily applied with the dip-coating method. Notably, the low Pt content required for catalyst loading decreased the cost.

\subsection{SEM characterization}

To promote anchoring of the coating to the metallic substrate and to increase the exposed area of the catalyst, FeCrAl fiber was thermally treated at $950{ }^{\circ} \mathrm{C}$ for $3 \mathrm{~h}$ in $\mathrm{O}_{2}$ atmosphere. To confirm that the applied thermal treatments enabled the formation of a uniform rough surface on the FeCrAl fiber, the morphology and composition of the fibers were studied. Fig. 4 and Table 1 show SEM micrographs and EDS analyses of the surfaces of the untreated and treated FeCrAl fibers. SEM micrographs of the untreated FeCrAl fiber are shown in Fig. 4a. The untreated FeCrAl fiber exhibited slightly cracked smooth surfaces. Additionally, the mass percentages of the elements ( $\mathrm{Fe}, \mathrm{Cr}$ and $\mathrm{Al}$ ) reported by EDS analysis were similar to those reported by the manufacturers. Fig. 4b shows SEM micrographs of the treated (calcined at $950^{\circ} \mathrm{C}$ for $3 \mathrm{~h}$ in $\mathrm{O}_{2}$ atmosphere) $\mathrm{FeCrAl}$ fiber, which showed the growth of uniformly roughened surfaces. ${ }^{22}$ Given that the bulk aluminum had a high chemical potential and was likely to be oxidized by oxygen, it easily migrated from the bulk to the surface and reacted with oxygen to form alumina
Table 1 Atomic composition of the sample determined by X-EDS

\begin{tabular}{llrr}
\hline Sample & Element & Weight/\% & Atomic/\% \\
\hline \multirow{2}{*}{ FeCrAl fiber } & Fe & 71.27 & 65.74 \\
& $\mathrm{Cr}$ & 22.41 & 22.20 \\
Calcined FeCrAl fiber & $\mathrm{Al}$ & 6.32 & 12.06 \\
& $\mathrm{Fe}$ & 30.75 & 15.93 \\
& $\mathrm{Cr}$ & 11.53 & 6.42 \\
$0.1 \mathrm{Pt} / \mathrm{FeCrAl}$ fiber & $\mathrm{Al}$ & 36.30 & 38.92 \\
& $\mathrm{O}$ & 21.42 & 38.74 \\
& $\mathrm{Fe}$ & 35.79 & 23.36 \\
& $\mathrm{Cr}$ & 4.67 & 3.44 \\
& $\mathrm{Al}$ & 29.15 & 24.36 \\
& $\mathrm{O}$ & 16.71 & 41.35 \\
& Pt & 13.68 & 7.49 \\
\hline
\end{tabular}

whiskers. ${ }^{31-33}$ In addition, the EDS analysis results of the thermally treated fibers indicated significant changes to the mass percentages of each element. Clearly, the percentages of $\mathrm{Al}$ and $\mathrm{O}$ increased, while that of Fe decreased because of the formation of the alumina layer by thermal treatment. ${ }^{34,35}$ The welladhered alumina coating promoted firm bonding of the active species to the metallic substrate. SEM micrographs of the monolithic catalyst are presented in Fig. 4c. The images show that the Pt catalyst formed a homogeneous surface on the whiskers or pores. The addition of Pt to the FeCrAl fiber was supported by the percentages reported by EDS analysis, which detected Pt content of approximately 13\%. This finding indicated that thermal treatment increased the exposed area of the FeCrAl fiber. This effect ensured catalytic activity by promoting the even dispersion of NPs. Moreover, ultrasound tests were conducted to confirm adherence between the wash-coated and active phases. The total weight losses of the samples were only 0.9 and $0.6 \mathrm{wt} \%$. These results indicated excellent adhesion between the wash-coated and active phases.

\subsection{XRD characterization}

The crystal phases of samples were identified by XRD. Fig. 5 shows the diffraction patterns of FeCrAl fiber before and after the treatments. XRD patterns of untreated FeCrAl fiber confirmed the presence of Fe-Cr alloys of ferrite type (PDF 540331). However, no diffraction peaks of $\mathrm{Al}$ were detected because the content of $\mathrm{Al}$ is very low. After calcination treatment at $950{ }^{\circ} \mathrm{C}$, the formation of the crystalline phase $\mathrm{Fe}_{2} \mathrm{AlCr}$ (PDF 54-0387) was found. This indicated that the percentage of $\mathrm{Al}$ increased after calcination; as confirmed from EDS analysis. Moreover, no diffraction peaks of alumina were detected, indicating high dispersion of the alumina layer. It should be noted that no Pt XRD peaks were observed for the $0.1 \mathrm{Pt} / \mathrm{FeCrAl}$ fiber catalyst, indicating the feature of highly dispersed Pt. Indeed, the TEM image clearly shows that Pt is highly dispersed with average particle size of only 2-4 $\mathrm{nm}$.

\subsection{Activity test}

The catalytic activities of the samples in toluene combustion were tested under the base condition of toluene inlet 


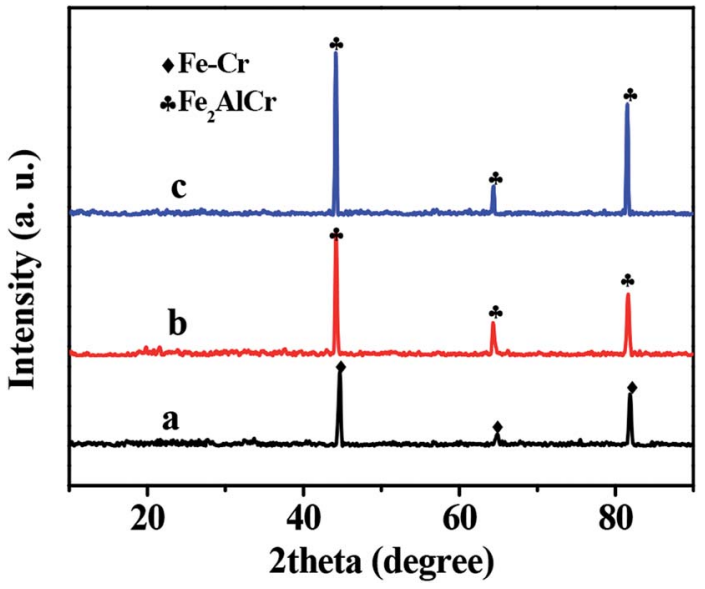

Fig. 5 XRD patterns of FeCrAl fiber (a), calcined FeCrAl fiber (b), 0.1Pt/ FeCrAl fiber (c).

concentration of $2500 \mathrm{ppm}$ and WHSV of $10000 \mathrm{~mL} \mathrm{~h}^{-1} \mathrm{~g}^{-1}$; the results are presented in Fig. 6a. In the blank experiment (without $\mathrm{Pt}$ ), no distinct toluene conversion was detected below $300{ }^{\circ} \mathrm{C}$ and gas chromatography (GC) detected the presence of other organic compounds in the gaseous product. These results indicated that the direct thermal oxidation of toluene under test conditions and in the absence of active species is negligible. ${ }^{36} \mathrm{In}$ contrast, the $0.1 \mathrm{Pt} / \mathrm{FeCrAl}$ fiber catalyst achieved complete toluene conversion (>99\%) at temperatures exceeding $280{ }^{\circ} \mathrm{C}$. This result, in addition to SEM and TEM observations, indicated that catalytic activity improved with the formation of a welladhered alumina coating on the surfaces of the FeCrAl fiber through thermal treatment and that 2-4 nm Pt NPs were highly dispersed on the surfaces of the alumina coating. In addition, mass spectroscopy (MS) results showed that the catalyst had nearly $100 \%$ selectivity for $\mathrm{CO}_{2}$ at a temperature of $280{ }^{\circ} \mathrm{C}$ (Fig. 6b). The ignition curves could be represented either by following the decrease in the toluene signal or by following the increase in $\mathrm{CO}_{2}$ signal. ${ }^{11}$ Furthermore, on-line MS did not detect CO during the reaction. This result indicated that our catalyst has high selectivity for $\mathrm{CO}_{2}$.

\subsection{Stability test}

To examine stability of the catalyst, we performed on-stream toluene combustion at $280{ }^{\circ} \mathrm{C}$ and WHSV of $10000 \mathrm{~mL} \mathrm{~h}{ }^{-1}$ $\mathrm{g}^{-1}$. The results are shown in Fig. 7. Clearly, the conversion rate of toluene was maintained at $100 \%$ and catalytic activity did not decrease during $600 \mathrm{~min}$ of on-stream reaction. This result suggested that the catalyst has excellent stability and can be applied in the industrial combustion of VOCs.

\subsection{Applicability test}

VOCs include alkanes, alcohols, ketones, esters and nitrogencontaining compounds. ${ }^{7,37}$ To confirm that the catalyst can be applied in the catalytic combustion of other VOCs, we tested the activities of the catalyst in the combustion of ethyl acetate, acetone, $n$-hexane, isopropyl alcohol (IPA) and $N, N$ -
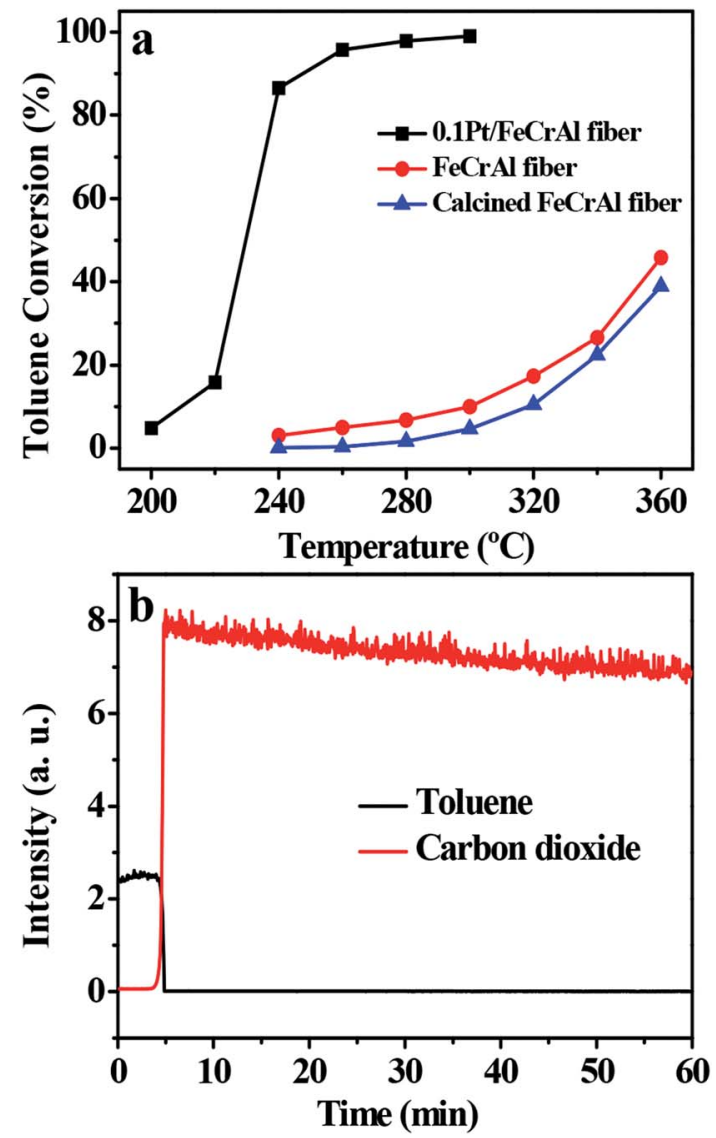

Fig. 6 Light-off curves of toluene catalytic combustion (a). MS curves of toluene catalytic combustion (temperature $=280^{\circ} \mathrm{C}$ ) (b). Other conditions: toluene concentration 2500 ppm and WHSV $10000 \mathrm{~mL}$ $\mathrm{h}^{-1} \mathrm{~g}^{-1}$.

dimethylformamide (DMF). The catalytic performance of $0.1 \mathrm{Pt} /$ FeCrAl fiber in VOC combustion is shown in Fig. 8. The temperatures for VOC conversion over $0.1 \mathrm{Pt} / \mathrm{FeCrAl}$ fiber catalyst for $10 \%\left(T_{10}\right), 50 \%\left(T_{50}\right)$ and $90 \%\left(T_{90}\right)$ of total conversion are summarized in Table 2 . We conclude that the catalytic

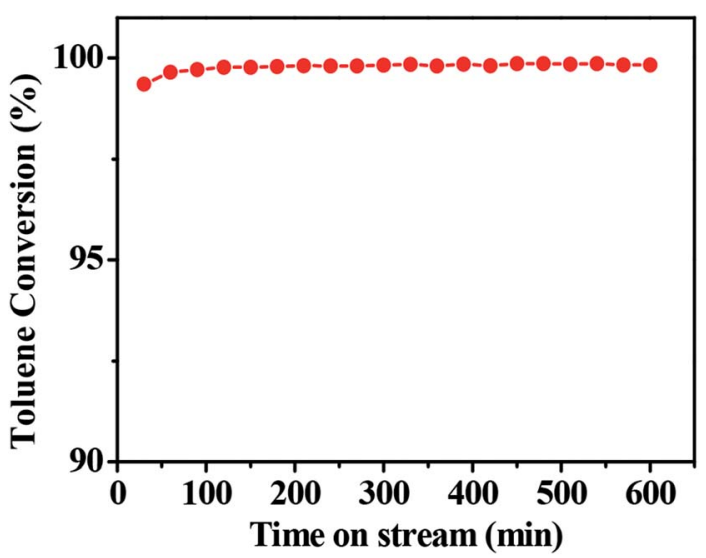

Fig. 7 The stability of toluene combustion over $0.1 \mathrm{Pt} / \mathrm{FeCrAl}$ fiber $(T=$ $280{ }^{\circ} \mathrm{C}$ ). Other conditions: toluene concentration $2500 \mathrm{ppm}$ and WHSV $10000 \mathrm{~mL} \mathrm{~h}^{-1} \mathrm{~g}^{-1}$. 


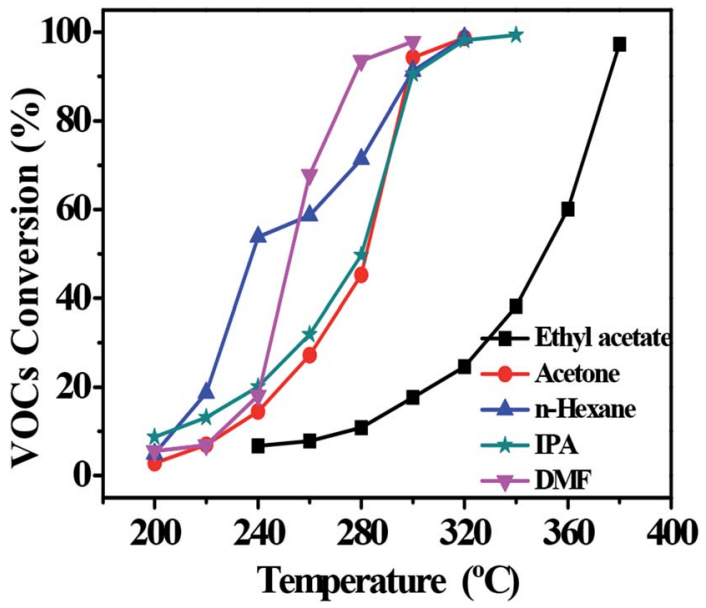

Fig. 8 Light-off curves of VOC catalytic combustion over 0.1Pt/FeCrAl fiber. Other conditions: VOC concentration of $2500 \mathrm{ppm}$ and WHSV of $10000 \mathrm{~mL} \mathrm{~h}^{-1} \mathrm{~g}^{-1}$.

Table 2 Comparison of catalytic activity of 0.1Pt/FeCrAl fiber for VOC combustion

\begin{tabular}{llll}
\hline VOCs & $T_{10} /{ }^{\circ} \mathrm{C}$ & $T_{50} /{ }^{\circ} \mathrm{C}$ & $T_{90} /{ }^{\circ} \mathrm{C}$ \\
\hline Toluene & 213 & 235 & 242 \\
DMF & 228 & 250 & 276 \\
$n$-Hexane & 214 & 238 & 295 \\
IPA & 212 & 280 & 298 \\
Acetone & 230 & 282 & 300 \\
Ethyl acetate & 280 & 350 & 374
\end{tabular}

activities of our catalyst for VOC combustion are hydrocarbon (nitrogen) > oxygenated compounds because hydrocarbon VOCs were strongly absorbed on the Pt catalyst and were quickly activated. These behaviors are similar to those reported in the literature. ${ }^{7,38}$ In addition, it can be illustrated that our catalyst can be applied to the catalytic combustion of different types of VOCs.

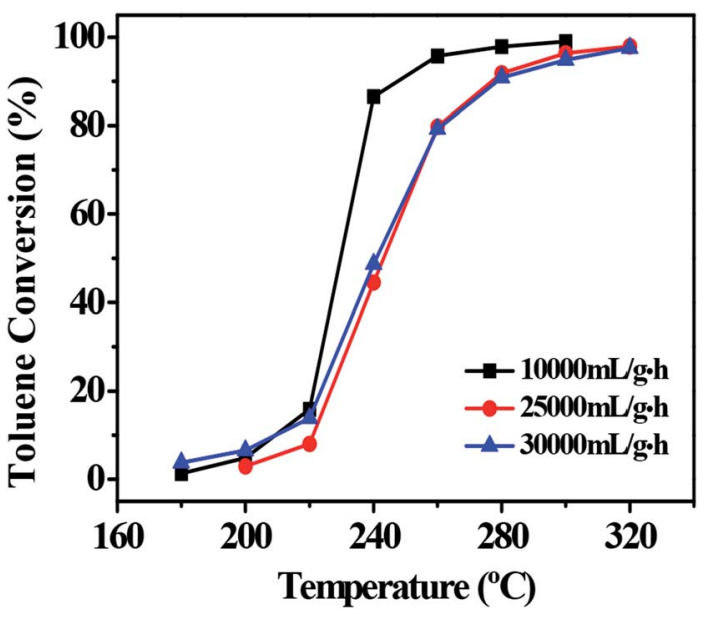

Fig. 9 Effect of space velocity on toluene combustion over 0.1Pt/ FeCrAl fiber. Other conditions: toluene concentration of $2500 \mathrm{ppm}$.

\subsection{Effect of space velocity}

Space velocity is an important parameter for the practical application of catalysts. ${ }^{39}$ To achieve high VOC combustion efficiency a high space velocity is required for catalysts. ${ }^{36}$ Hence, the catalytic behavior of the $0.1 \mathrm{Pt} / \mathrm{FeCrAl}$ fiber in the catalytic combustion of toluene under three different WHSV values was tested (Fig. 9). ${ }^{40}$ Increasing the WHSV values decreased the toluene conversion at the same reaction temperature. This result may be attributed to the shortened residence time of toluene in the catalyst bed at high WHSV. Nevertheless, the result suggested that the catalyst could be used to catalyze the conversion of high VOC fluxes. Thus, our catalyst has considerable application potential in the environmental catalysis field.

\section{Conclusions}

Highly dispersed Pt NPs dispersion liquid was prepared via the solvent-thermal method. A well-adhered alumina layer was formed on the surfaces of FeCrAl fibers through thermal treatment. Then, the supported catalyst was fabricated by simply spraying the dispersion liquid on the FeCrAl fibers. Active species were randomly loaded on the surfaces of FeCrAl fibers by spraying. In addition, the catalyst with Pt loading of $0.1 \mathrm{wt} \%$ delivered $100 \%$ toluene conversion and high $\mathrm{CO}_{2}$ selectivity at the space velocity of $10000 \mathrm{~mL} \mathrm{~h}^{-1} \mathrm{~g}^{-1}$. Moreover, the catalyst was stable for at least $600 \mathrm{~min}$ without deactivation. The intrinsic activity of the catalyst is intimately related to the high dispersion of 2-4 nm Pt NPs on the surfaces of the alumina coating. Furthermore, we believe that this strategy will provide a new route for the preparation and application of environmental metallic monolithic catalysts.

\section{Conflicts of interest}

There are no conflicts to declare.

\section{Acknowledgements}

This study was supported by the Natural Science Foundation of China (No. 21506194, No. 21676255), the Natural Science Foundation of Zhejiang Province (No. Y16B070011), and the Commission of Science and Technology of Zhejiang province (No. 2017C03007, No. 2017C33106).

\section{Notes and references}

1 H. Wang, W. Yang, P. Tian, J. Zhou, R. Tang and S. Wu, Appl. Catal., A, 2017, 529, 60-67.

2 H. Lu, Y. Zhou, W. Han, H. Huang and Y. Chen, Catal. Sci. Technol., 2013, 3, 1480-1484.

3 S. Scire, S. Minico, C. Crisafulli, C. Satriano and A. Pistone, Appl. Catal., B, 2003, 40, 43-49.

4 H. Huang, Y. Xu, Q. Feng and D. Y. Leung, Catal. Sci. Technol., 2015, 5, 2649-2669.

5 B. Li, J. Wang and H. Gong, Catal. Today, 2009, 148, 81-87. 
6 S. Xie, Y. Liu, J. Deng, J. Yang, X. Zhao, Z. Han and H. Dai, Catal. Sci. Technol., 2018, 8, 806-816.

7 M. S. Kamal, S. A. Razzak and M. M. Hossain, Atmos. Environ., 2016, 140, 117-134.

8 Y. Wang, L. Guo, M. Chen and C. Shi, Catal. Sci. Technol., 2018, 8, 459-471.

9 W. Zhang and D. Wu, Ceram. Int., 2016, 42, 16563-16570.

10 K. S. Yang, J. S. Choi and J. S. Chung, Catal. Today, 2004, 97, 159-165.

11 N. Burgos, M. Paulis, M. M. Antxustegi and M. Montes, Appl. Catal., B, 2002, 38, 251-258.

12 W. Fei, S. C. Kuiry and S. Seal, Oxid. Met., 2004, 62, 29-44.

13 L. M. Martinez, O. Sanz, M. I. Dominguez, M. A. Centeno and J. A. Odriozola, Chem. Eng. J., 2009, 148, 191-200.

14 M. Valentini, G. Groppi, C. Cristiani, M. Levi, E. Troncoin and P. Forzatti, Catal. Today, 2001, 69, 307-314.

15 S. Cimino, A. Gambriasi, L. Lisi, G. Mancino, M. Musiani, L. Vázquez-Gómez and E. Verlato, Chem. Eng. J., 2016, 285, 276-285.

16 H. Sun, X. Quan, S. Chen, H. M. Zhao and Y. Zhao, Appl. Surf. Sci., 2007, 253, 3303-3310.

17 O. Sanz, F. J. Echave, M. Sánchez, A. Monzón and M. Montes, Appl. Catal., A, 2008, 340, 125-132.

18 C. Wang, L. Han, P. Chen, G. Zhao, Y. Liu and Y. Lu, J. Catal., 2016, 337, 145-156.

19 C. Wang, L. Han, Q. Zhang, Y. Li, G. Zhao, Y. Liu and Y. Lu, Green Chem., 2015, 17, 3762-3765.

20 Y. Diaz, A. Sevilla, A. Mónaco, F. J. Méndez, P. Rosales, L. Garcia and J. L. Brito, Fuel, 2013, 110, 235-248.

21 J. E. Samad, J. A. Nychka and N. V. Semagina, Chem. Eng. J., 2011, 168, 470-476.

22 B. P. Barbero, L. Costa-Almeida, O. Sanz, M. Morales, L. E. Cadus and M. Montes, Chem. Eng. J., 2008, 139, 430435.
23 I. Yuranov, N. Dunand, L. Kiwi-Minsker and A. Renken, Appl. Catal., B, 2002, 36, 183-191.

24 L. Wu, A. Mendoza-Garcia, Q. Li and S. Sun, Chem. Rev., 2016, 116, 10473-10512.

25 P. Hou, H. Liu, J. Li and J. Yang, CrystEngComm, 2015, 17, 1826-1832.

26 C. Shen, C. Hui, T. Yang, C. Xiao, J. Tian, L. Bao, S. Chen, H. Ding and H. Gao, Chem. Mater., 2008, 20, 6939-6944.

27 Y. Wang, Y. Xue, C. Zhao, D. Zhao, F. Liu, K. Wang and D. D. Dionysiou, Chem. Eng. J., 2016, 300, 300-305.

28 W. Zhang, L. Hu, F. Wu and J. Li, Catal. Lett., 2017, 147, 407415.

29 L. Pérez-Mirabet, E. Solano, F. Martínez-Julián, R. Guzmán, J. Arbiol, T. Puig, X. Obradors, A. Pomar, R. Yáňez, J. Ros and S. Ricart, Mater. Res. Bull., 2013, 48, 966-972.

30 W. Wang, L. Zhuang, Y. Zhang and H. Shen, Mater. Res. Bull., 2015, 69, 61-64.

31 P. Avila, M. Montes and E. E. Miró, Chem. Eng. J., 2005, 109, 11-36.

32 S. Zhao, J. Zhang, D. Weng and X. Wu, Surf. Coat. Technol., 2003, 167, 97-105.

33 S. Govender and H. B. Friedrich, Catalysts, 2017, 7, 62.

34 J. M. Zamaro, M. A. Ulla and E. E. Miró, Appl. Catal., A, 2006, 308, 161-171.

35 J. Jia, J. Zhou, J. Zhang, Z. Yuan and S. Wang, Appl. Surf. Sci., 2007, 253, 9099-9104.

36 L. Lin and H. Bai, Chem. Eng. J., 2016, 291, 94-105.

37 Z. Zhang, Z. Jiang and W. Shangguan, Catal. Today, 2016, 264, 270-278.

38 L. F. Liotta, Appl. Catal., B, 2010, 100, 403-412.

39 H. Li, C.-Y. Wu, Y. Li and J. Zhang, Appl. Catal., B, 2012, 111, 381-388.

40 C. W. Ahn, Y. W. You, I. Heo, J. S. Hong, J. K. Jeon, Y. D. Ko, Y. H. Kime, P. Hosik and J. K. Suh, J. Ind. Eng. Chem., 2017, 47, 439-445. 